\title{
Interesterification and acidolysis of butterfat with oleic acid by Mucor javanicus lipase: changes in the pool of fatty acid residues
}

\author{
Victor M. Balcão and F. Xavier Malcata \\ Escola Superior de Biotecnologia, Universidade Católica Portuguesa, Porto, Portugal \\ Lipases have become powerful tools in the manufacture of structured fats either via randomization of their \\ glyceride composition or incorporation of externally supplied fatty acid residues in such glycerides. The \\ present communication reports on changes that occurred in the fatty acid pool of anhydrous butterfat subject \\ to interesterification and to acidolysis with oleic acid catalyzed by a commercial lipase immobilized by plain \\ physical adsorption onto hydrophobic hollow fibers at $40^{\circ} \mathrm{C}$ under controlled water activity. The main goal \\ of this research effort was to engineer butterfat so as to increase its level of unsaturated fatty acid residues \\ and concomitantly decrease its level of medium-and long-chain saturated fatty acid residues (viz. lauric and \\ myristic acids). Although a certain degree of net hydrolysis of butterfat was observed, the triacylglycerols \\ of butterfat subject to acidolysis were found to possess more (approximately $30 \% \mathrm{w} / \mathrm{w}$ ) oleic acid and \\ significantly less $(8 \% \mathrm{w} / \mathrm{w})$ lauric acid and less $(2 \% \mathrm{w} / \mathrm{w})$ myristic acid than those of the original butterfat.
}

Keywords: Immobilized lipase; acidolysis; butter; hollow-fiber reactor; free fatty acids; randomization

\section{Introduction}

Milkfat is an important source of dietary fat and imparts excellent flavor and mouthfeel when present in formulated food products. For a number of years, however, several queries have been raised pertaining to the value of milkfat owing to health considerations. ${ }^{1}$ Milkfat has been seen as bad for health because it contains reasonable amounts of cholesterol and primarily saturated fatty acid residues ${ }^{2,3}$ which have been implicated in promotion of coronary heart disease. $^{4}$ The health hazards posed by saturated fats in human diets are largely due to lauric, myristic and palmitic acids ${ }^{2}$ conversely, Davide $^{1}$ and $\mathrm{O}^{\prime}$ Donnell $^{5}$ have shown that oleic acid (C18:1) is effective in lowering plasma cholesterol levels, e.g. when it replaces palmitic acid (C16:0) in the human diet. Short-chain fatty acids, on the other hand, do not play any apparent role with respect to the cholesterol level. $^{6}$

Address reprint requests to Dr. F. X. Malcata, Universidade Catolica Portuguesa, Escola Superior de Biotecnologia, Rua Dr. Antonio Bernardino Almeida, P-4200 Porto, Portugal
Engineering of milkfat aimed at improving its nutritional quality may thus take the form of changes in the combination of fatty acid residues in the glycerol backbone of triacylglycerols. ${ }^{7}$ Currently available technology for commercial modification of milkfat includes mixing, hydrogenation, fractionation and bulk chemical synthesis, but these processes either perform poorly or are aggressive to the fine milky flavor (due to use of chemical reactants and/or solvents under high temperatures which often require post processing refining). Alternatively, lipase-catalyzed reactions have attracted an increased interest over the past decade because these enzymes possess unusual selectivity and specificity toward their natural substrates (i.e., fatty acid moieties) and in their action mimic environment friendly (bio)chemical routes. One of the best-known examples of enzymatic engineering of fats is the production of cocoa butter substitutes. $^{8}$ The potential of 1,3 -specific lipases for manufacture of cocoa butter substitutes relies on enzymecatalyzed transesterification or acidolysis of a nonexpensive oil such as palm oil with tristearin or stearic acid, respectively. ${ }^{9}$ Similar uses of lipases include interesterification of such vegetable oils as canola, ${ }^{10}$ acidolysis of palm oil with oleic acid, ${ }^{9}$ manufacture of medium-chain triacylglycerols of octanoic and decanoic acids which are mostly used to 
provide a dense energy source to patients with pancreatic insufficiency, ${ }^{9}$ and lipase-mediated incorporation of $\omega 3$ fatty acids into vegetable oils and concentration of $\omega 3$ fatty acid residues in fish oil, ${ }^{8}$ e.g., via acidolysis of cod liver oil with eicosapentaenoic and docosahexaenoic acids using a lipase from Mucor miehei. ${ }^{11}$

This research effort was focused on the modification of milkfat via interesterification reactions of plain butterfat or via acidolysis reactions with oleic acid catalyzed by a lipase produced by Mucor javanicus and immobilized by physical adsorption onto a bundle of polypropylene hollow fibers with plain melted butterfat or melted butterfat added with free oleic acid pumped through the lumen and the shell sides. Since our study aimed primarily at producing butterfat with a higher content of oleic acid residues and lower contents of saturated medium- and long-chain residues, the lipase was selected so as to possess specificity for fatty acid moieties in that length range.

\section{Materials and methods}

\section{Materials}

Lipase. The lipase used (obtained from the mold $M$. javanicus) was a commercial crude powder (M10 ${ }^{\mathrm{TM}}$ ) kindly supplied by Amano Pharmaceutical (Nagoya, Japan).

Chemicals. All chemicals purchased were used without further purification. Potassium carbonate, Coomassie brilliant blue G-250, albumin fraction $\mathrm{V}$ (from bovine blood serum) and anhydrous sodium sulfate were obtained from Merck (Darmstadt, Germany); 18-crown-6-ether was purchased from Merck (München, Germany); butylated hydroxyanisole, $p$-bromophenacylbromide and potassium phosphate were from Sigma (St. Louis, MO). Chloroform, formic acid, acetonitrile $\left(190^{\mathrm{TM}}\right)$ and methanol $\left(205^{\mathrm{TM}}\right)$ were from ROMIL Chemicals (Leicester, U.K.). Isooctane was purchased from Rathburn Chemicals (Walkerburn, Scotland). The free fatty acid standards ( $>99.9 \%$ pure) were obtained from Sigma. Fermentation ethanol (96\% v/v) was obtained from AGA (Sacavém, Portugal). Dry nitrogen $\left(\mathrm{C}-55^{\mathrm{TM}}\right)\left(<1 \mathrm{ppm} \mathrm{H}_{2} \mathrm{O}\right.$ and $<1 \mathrm{vpm} \mathrm{O}_{2}$ ) and liquid nitrogen were purchased from Carburos Metalicos (Barcelone, Spain). The deionized water used possessed a final conductivity of $18.2 \mathrm{M} \Omega \mathrm{cm}^{-1}$ and was produced in a Milli-Q Plus 185 system (Molsheim, France). Tripelargonin (TAG27) standard (99\% purity) was purchased from Merck. The standard mixture GLC74 for fatty acid methyl esters was purchased from Nu-Chek Prep (Elysian MN) whereas the standard mixtures for branched-chain fatty acid methyl esters (89-1052 QUAL MIX BR2 and 89-1054 QUAL MIX BR4) were purchased from Larodan Fine Chemicals (Malmö, Sweeden).

Substrates. Salt-free, pasteurized butter was purchased from PROLEITE (Oliveira de Azeméis, Portugal) and kept in sealed plastic bags of approximately $1.5 \mathrm{~kg}$ at $-30^{\circ} \mathrm{C}$ until use. Oleic acid (extra pure) was obtained from Riedel-de-Haën (Seelze, Germany).

\section{Apparata}

Experimental setup. A laboratory module of microporous polypropylene membranes in hollow-fiber form (Liqui-Cell ${ }^{\mathrm{TM}}$ $X$ 10/240) was purchased from Hoechst Celanese (Charlotte, $\mathrm{NC})$. This unit (30 cm long and $2.5 \mathrm{~cm}$ in diameter) encases approximately 1,000 fibers ( $23 \mathrm{~cm}$ long) with a nominal internal diameter of $240 \mu \mathrm{m}$. The water bath was equipped with a mechanical agitator and a temperature controller (Julabo Labortechnik, Seelbach, Germany). Recirculation of fluids was achieved with high precision metering pumps (ISMATEC MC-Z, Zürich, Switzerland).

Analytical equipment. Nylon membrane filters (NALGENETM, $0.45 \mu \mathrm{m}$ ) were purchased from Nalge (New York NY). Disposable cuvettes for spectrophotometric readings were purchased from Kartell (Binasco, Italy). The HPLC equipment utilized (Beckman Instruments, San Ramon, CA) consisted of an autosampler with temperature control for the column (model 502), a C-18 reversed-phase column $(25 \mathrm{~cm} \times 4.6 \mathrm{~mm}$ I.D. $\times$ $5 \mu \mathrm{m}$ film thickness) coupled with a precolumn cartridge (4.5 $\mathrm{cm}$ ), a solvent delivery system with two pumps (Programmable Solvent Module 126), a programmable multiwavelength spectrophotometer (Diode Array Detector Module 168), and a software package for system control and data acquisition (GOLD v6.01). The GC equipment consisted of a gas chromatograph (MicroMat model HRGC 412, from HNU-Nordion, Helsinki, Finland) equipped with a split-splitless injector, a flame-ionization detector and a HP-INNOWAX (cross-linked polyethylene glycol) silica capillary column $(30 \mathrm{~m} \times 0.25 \mathrm{~mm}$ I.D.) (from Hewlett-Packard, Avondale, PA) with $0.25 \mu \mathrm{m}$ film thickness. The solvent evaporation unit consisted of a Reacti-Therm ${ }^{\mathrm{TM}}$ Heating module (model 18790) coupled with a Reacti-Vap ${ }^{\mathrm{TM}}$ Evaporating unit (model 18780) from Pierce (Rockford, IL).

\section{Methods}

Preparation of anhydrous butterfat. Prior to lipase-catalyzed reactions, butter was pretreated by the procedure of Kalo et al. ${ }^{12}$ with slight modifications as described in detail by Balcão and Malcata. ${ }^{13}$ Water was removed from butter in a separating funnel at $60^{\circ} \mathrm{C}$ and fat was then filtered out using normal filter paper and dried in a vacuum of approximately 800 mbar for $1 \mathrm{~h}$ in a boiling waterbath. After drying via passage through a silica column, nitrogen was bubbled in the melted butterfat for approximately $1 \mathrm{~h}$ (to help in removing residual oxygen and water), and the dried fat thus obtained was stored under sealed conditions at $-30^{\circ} \mathrm{C}$ until experimental use.

Preparation of reagent solutions. The McIlvaine buffer and the working solution of Coomassie reagent were prepared according to procedures described elsewhere. ${ }^{14}$

Assay for protein. The amount of protein adsorbed on the fibers of the reactor was obtained as the difference between the protein content of the supernatant solutions before and after the immobilization procedure. The assays for protein followed the Coomassie Brilliant Blue G-250 method which consists in adding $0.5 \mathrm{ml}$ aliquots of the solution of crude lipase in McIlvaine buffer to 4.5 $\mathrm{ml}$ of Coomassie reagent followed by measuring absorbance after $5 \mathrm{~min}$ at $595 \mathrm{~nm}$ using disposable cuvettes. Plain McIlvaine buffer was used as the blank. Protein content was determined from such absorbance readings by means of a calibration curve previously prepared with aqueous solutions of bovine serum albumin (BSA) with concentrations ranging from 0 to $500 \mu \mathrm{g} \mathrm{ml}^{-1}$.

Immobilization of lipase. Immobilization of the crude commercial lipase preparation onto the hydrophobic polypropylene hollow fibers followed the previous protocol by Balcão et al. ${ }^{14}$ and Balcão and Malcata. ${ }^{13}$

Interesterification reactions. Modification of plain butterfat via interesterification and acidolysis reactions with oleic acid, catalyzed by immobilized lipase, were performed at $40^{\circ} \mathrm{C}$ using the 


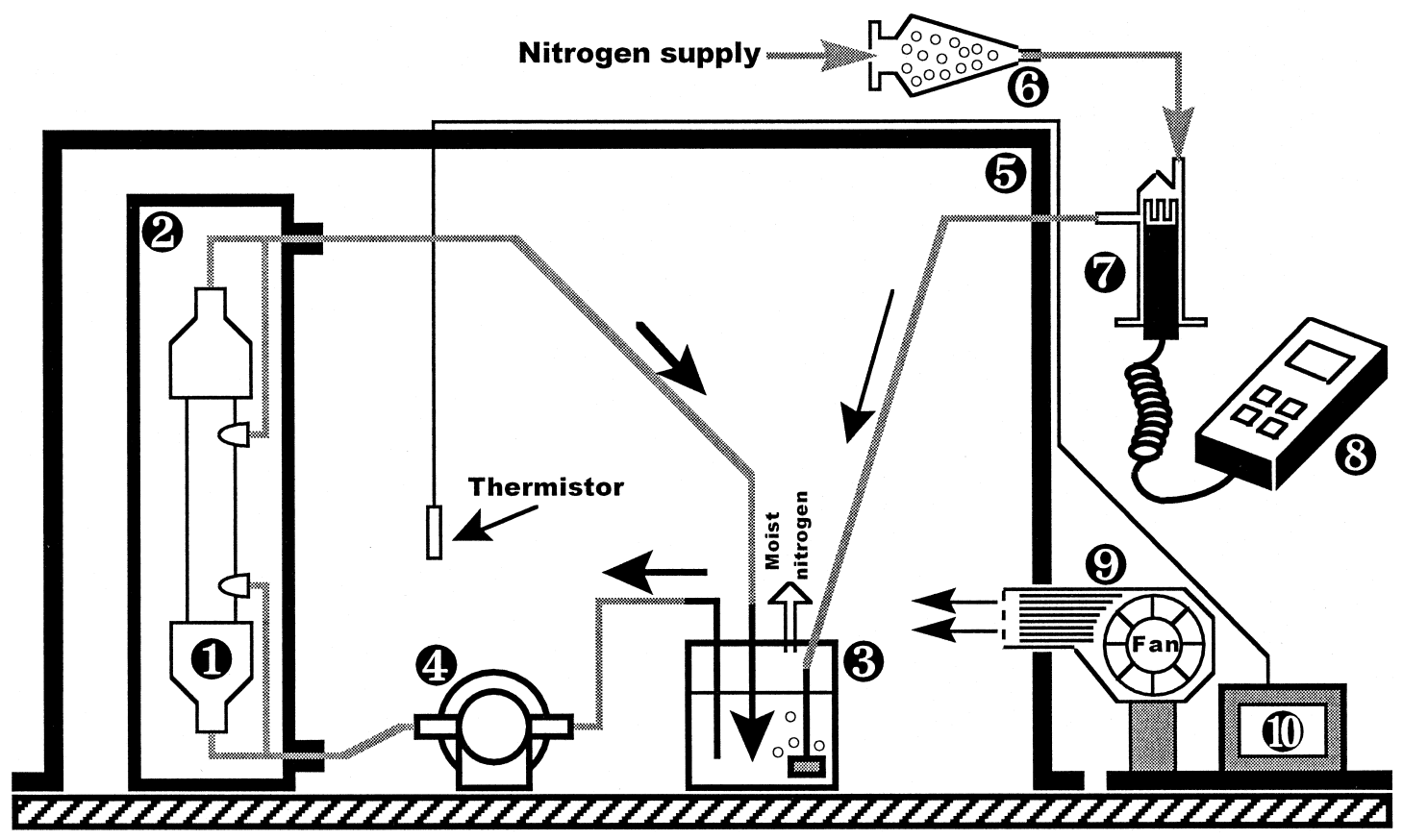

Figure 1 Experimental setup used for the lipase-catalyzed interesterification and acidolysis of butterfat. Hollow-fiber bioreactor, (0; thermostatted waterbath, 2; stirred beaker containing melted butterfat, (3; high precision gear pump, 4; Perspex dome, 6; ampoule containing silica gel, $\mathbf{6}$; moisture probe, $\mathbf{0}$; thermohygrometer, 8; blower, $\mathbf{9}$; electronic control (1)

experimental setup depicted in Figure 1. Once the lipase immobilization procedure was complete, and immediately before start up of each experiment, the following sequence of procedures was followed: the reactor was placed upside down and the reactant mixture [butterfat alone or melted dry butterfat added with $50 \%$ $(\mathrm{v} / \mathrm{v})$ oleic acid] was pumped through the reactor (so as to completely replace the aqueous buffer in the lumen- and shellsides of the fibers), the reactor was reverted to its regular operating position (inlet streams at the bottom) and the reactant mixture was circulated for an extra 2 min (before starting the stopwatch). The whole system was kept under a perspex dome with the air temperature controlled at approximately $40^{\circ} \mathrm{C}$. Volumes of plain butterfat, or melted dry butterfat added with oleic acid, typically ranging from 350 to $375 \mathrm{ml}$, were recirculated for approximately $150 \mathrm{~h}$ through the lumen and shell sides of the hollow fibers at flow rates of approximately $35 \mathrm{ml} \mathrm{h}^{-1}$ and approximately $31 \mathrm{ml}$ $\mathrm{h}^{-1}$, respectively, in order to obtain similar space times in both sides. Dried nitrogen was bubbled into the recirculating fat mixture in the beaker throughout each experiment. Aliquots were withdrawn at regular time intervals from the beaker containing the recirculating fat mixture and assayed for composition of free fatty acids and fatty acid residues.

Assays for free fatty acids. Free fatty acids in butterfat were analyzed by HPLC following the procedure by Garcia et al. ${ }^{15}$ with modifications. For calibration, stock solutions of 12 different free fatty acid standards, viz. C4:0 (butyric acid), C6:0 (caproic acid), C8:0 (caprylic acid), C10:0 (capric acid), C12:0 (lauric acid), C14:0 (myristic acid), C16:0 (palmitic acid), C18:0 (stearic acid), C18:1 (oleic acid), C18:2 (linoleic acid), C18:3 (linolenic acid), and $\mathrm{C} 20: 0$ (arachidic acid) were prepared so as to obtain a final concentration of approximately $0.200 \mathrm{~mol} \mathrm{l}^{-1}$ for each free fatty acid standard, added with internal standards, viz. C9:0 (pelargonic acid) and C17:0 (margaric acid), and stabilized with $0.05 \%$ butylated hydroxyanisole as described in detail by Balcão and Malcata. ${ }^{13}$ The stock solutions were then duly mixed in order to obtain five mixtures with increasing concentrations of every free fatty acid. Derivatization of the free fatty acids in calibration standards as well as in actual experimental samples followed the procedures described in detail by Balcão and Malcata. ${ }^{13}$ Following refrigeration for at least $1 \mathrm{~h}$ (at approximately $4^{\circ} \mathrm{C}$ ), samples were cold filtered through $0.45 \mu \mathrm{m}$ nylon membrane filters. Aliquots of $20 \mu \mathrm{l}$ of the filtered samples were injected into the reversed-phase column coupled with a precolumn cartridge; separation was effected at $33^{\circ} \mathrm{C}$ using a mobile phase of water, methanol and acetonitrile under the following gradient pattern: $45 \%$ water (W) before startup, $11 \%$ (W) for 20 min, from $11 \%$ (W) to $0 \%$ (W) during $7 \mathrm{~min}$ with a moderately convex variation, at $0 \%$ (W) during $4 \mathrm{~min}$, from $0 \%(\mathrm{~W})$ to $45 \%(\mathrm{~W})$ during $18 \mathrm{~min}$ with a rapid concave variation and at $45 \%(\mathrm{~W})$ during $21 \mathrm{~min}$. In all cases, acetonitrile was maintained at $5 \%$. The flow rate of eluant was 1 $\mathrm{ml} \mathrm{m^{-1 }}$ and absorbance of the eluate was read at $254 \mathrm{~nm}$. The parameters of the linear regressions to the calibration data are depicted in Table 1.

Assays for fatty acid residues. The (esterified) fatty acid composition of triacylglycerols (TAG) of samples of reaction products was determined by gas chromatography using a split-splitless injector (split $1: 20$ at $225^{\circ} \mathrm{C}$ ) and a flame ionization detector (at $250^{\circ} \mathrm{C}$ ). The fatty acid methyl esters (FAME) were separated on a HP-INNOWAX column using helium as carrier gas (inlet pressure $1.2 \mathrm{bar}$ ). The temperature program was: after $3 \mathrm{~min}$ at $50^{\circ} \mathrm{C}$, the temperature was raised $10^{\circ} \mathrm{C} \min ^{-1}$ to $195^{\circ} \mathrm{C}$, and after an isothermal period of $1 \mathrm{~min}$, the temperature was raised $1^{\circ} \mathrm{C} \mathrm{min}{ }^{-1}$ to $220^{\circ} \mathrm{C}$, and then held at that value for $5 \mathrm{~min}$. The triacylglycerols of reaction mixtures were transesterified to methylesters with sodium methoxide in methanol as follows: $10 \mu \mathrm{l}$ of melted reaction product were accurately weighted into a screw-capped vial into which $1.0 \mathrm{ml}$ of TAG27 solution $\left(83.6 \mu \mathrm{g} \mathrm{ml}{ }^{-1}\right.$ isooctane) was added. Solvent was then evaporated under a gentle stream of nitrogen $\left(\right.$ at $40^{\circ} \mathrm{C}$ ) and $600 \mu$ l of hexane were then added, followed by addition of $6 \mu \mathrm{l}$ of sodium methoxide ( $2 \mathrm{~mol}$ 
Table 1 Values obtained for parameters $\alpha$ and $\beta$ and corresponding coefficients of determination, $\rho^{2}$, for the calibration curves obtained for each free fatty acid standard

\begin{tabular}{lcccc}
\hline Free Fatty & $\begin{array}{c}\text { Internal Standard } \\
\text { Used in the } \\
\text { Andid Standard }\end{array}$ & & & \\
\hline Analysis & $\alpha$ & $\beta$ & $\rho^{2}$ \\
\hline C6:0 & C9:0 & 0.361 & 0.305 & 0.999 \\
C8:0 & C9:0 & 0.599 & 0.132 & 0.999 \\
C10:0 & C9:0 & 0.579 & 0.223 & 0.997 \\
C12:0 & C9:0 & 0.666 & 0.185 & 0.999 \\
C18:3 & C9:0 & 0.716 & 0.0637 & 0.999 \\
C14:0 & C17:0 & 0.755 & 0.284 & 0.998 \\
C18:2 & C17:0 & 0.468 & -0.0594 & 0.994 \\
C16:0 & C17:0 & 0.648 & 0.0815 & 0.999 \\
C18:1 & C17:0 & 0.792 & 0.319 & 0.999 \\
C18:0 & C17:0 & 0.523 & -0.00655 & 0.994 \\
C20:0 & C17:0 & 0.678 & 0.428 & 0.998 \\
& C17:0 & 0.959 & 0.295 & 0.990 \\
\hline
\end{tabular}

The equations of the calibration curves are of the form $C_{u n k} /$ $\mathrm{C}_{\text {Int.Std. }}=\alpha \cdot\left[\mathrm{A}_{\text {unk }} / \mathrm{A}_{\text {Int.Std. }}\right]+\beta$ where $\mathrm{C}_{\text {unk }}$ is the unknown concentration of a given peak $\left(\mathrm{mmol} \mathrm{I}^{-1}\right), \mathrm{A}_{\text {unk }} / \mathrm{A}_{\text {Int.Std. }}$ is the ratio of the area of the unknown peak to the area of the corresponding internal standard and $\mathrm{C}_{\text {Int.Std. }}$ is the concentration of the internal standard solution used $\left(\mathrm{mmol} \mathrm{I}^{-1}\right)$

$1^{-1}$ in methanol). In addition to the catalytic amount of sodium methoxide, a sufficient amount of sodium methoxide was added to neutralize the free fatty acids. ${ }^{16}$ Following vigorous homogenization for approximately $1 \mathrm{~min}$ in a vortex, centrifugation at $800-1000 \mathrm{rpm}$ was performed for approximately $10 \mathrm{~min}$ after which $1 \mu \mathrm{l}$ of clear supernatant was immediately injected. Mass and molar response factors for FAMEs of interest were determined by analyzing a standard mixture (GLC74) via seven injections of $1 \mu \mathrm{l}$ of a $1 \%$ solution $(\mathrm{w} / \mathrm{v})$ in hexane. For quantification of branched-chain fatty acids, two standard mixtures were analyzed (89-1052 QUAL MIX BR2 and 89-1054 QUAL MIX BR4). For other FAMEs, molar response factors were calculated by nonlinear regression of the (average) molar response factors for FAMEs from GLC74 as a function of the number of carbon atoms (correlation coefficient of nonlinear regression was 0.999, Figure 2) using the program TableCurve ${ }^{\mathrm{TM}}$ v. 1.0 from Jandel Scientific (San Rafael CA).

\section{Results}

The protein content of the crude $\mathrm{M} 10^{\mathrm{TM}}$ lipase powder was approximately $9.74 \%$ (w/w; BSA equivalent). The amount of protein adsorbed onto the hollow fibers was $6.36 \mu \mathrm{g}$ protein $/ \mathrm{cm}^{-2}$ membrane, and corresponded to an immobilization yield of approximately $54 \%$ of the protein in the supernatant solution. Typical gas chromatograms of fatty acid methyl esters of plain butterfat with added pelargonic acid and of standard mixtures of FAMEs are depicted in Figure 3. The results pertaining to the concentrations of free fatty acids in butterfat undergoing lipase-catalyzed interesterification are plotted in Figures 4 and 5 for interesterification of plain butterfat and acidolysis of butterfat with oleic acid, respectively. As can be seen in Figure 4a, the concentrations of the small- and medium-chain saturated free fatty acids increased slightly throughout the reaction time frame except for lauric and myristic acids which increased by 3 - and 25-fold, respectively, during the first
$80 \mathrm{~h}$ of reaction. With respect to the saturated free fatty acid residues with long carbon chains (Figure $4 b$ ), the highest increase observed was for palmitic acid (6.4-fold). Regarding the changes in free fatty acids during the acidolysis reaction, small- and medium-chain saturated fatty acid moieties displayed only a slight increase in concentration during the entire reaction time frame (Figure 5a) except for lauric and myristic acids which increased by 1.4and 2.1-fold, respectively, during the first $50 \mathrm{~h}$ of reaction. In terms of the saturated free fatty acid residues with long carbon chains (Figure $5 b$ ), the highest increase observed was for palmitic acid (1.2-fold). Oleic acid, initially added in free form to the acidolysis reaction medium, was found to disappear (due to incorporation in the triacylglycerols of butterfat) by $5.1 \%$ within $150 \mathrm{~h}$ of reaction.

The increase in concentration of total free fatty acids was, in both cases, in agreement with the net reduction of approximately $50 \mathrm{ppm}$ in the water content of the reaction medium probably due to hydrolysis promoted by residual buffer trapped inside the hollow fibers prior to formal startup of sampling. This observation, which suggests an initial degree of hydrolysis of approximately $2.5 \%$ and $18.1 \%$ at startup of interesterification of plain butterfat and acidolysis of butterfat with oleic acid, respectively, is based on the total mass of fatty acid residues esterified in the triacylglycerols of butterfat, approximately $311.9 \mathrm{~g}$ in $375 \mathrm{ml}$ of original plain butterfat (Figure 6), and approximately $145.3 \mathrm{~g}$ in $350 \mathrm{ml}$ of a $50 \%(\mathrm{v} / \mathrm{v})$ mixture of butterfat added with free oleic acid (Figure 7), and on the total mass of free fatty acid residues at startup, approximately $7.8 \mathrm{~g}$ in plain butterfat and approximately $26.3 \mathrm{~g}$ (except oleic acid) in butterfat used for acidolysis reactions.

The profile of fatty acid residues in the modified butterfat throughout reaction time is depicted in Figures 6 and 7 for interesterification of plain butterfat and acidolysis of butterfat with oleic acid, respectively. Recalling the average

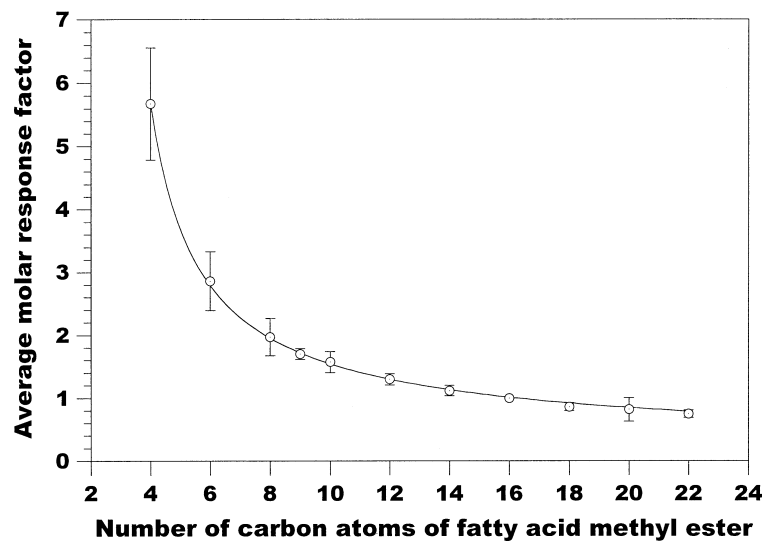

Figure 2 Average molar response factors (MLRF) for fatty acid methyl esters. Experimental data $(O)$ and theoretical fit $(-)$ using the relationship MLRF $=1 /\{\alpha+\beta \times \sqrt{\text { FAMECN }}\}$ where FAMECN stands for fatty acid methyl ester carbon number. The best parameter estimates are given by $\alpha=-0.631 \pm 0.039$ and $\beta=0.404 \pm 0.019\left(\rho^{2}=0.999\right)$. Experimental points include error bars with $99.9 \%$ confidence intervals 

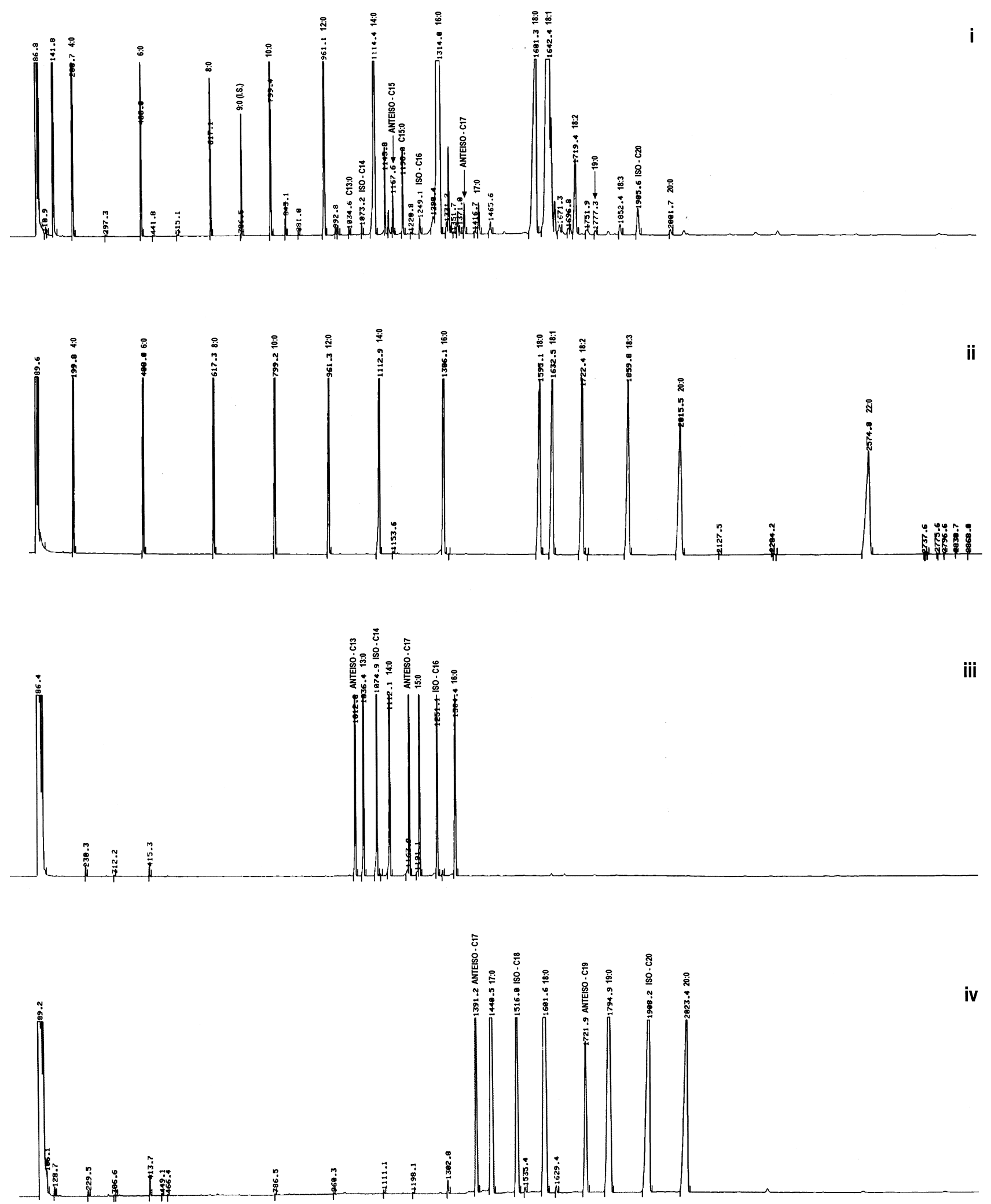

Figure 3 Gas chromatograms of fatty acid methyl esters of plain butterfat with added pelargonic acid (i), GLC74 standard mixture of fatty acid methyl esters (ii), QUAL MIX BR2 standard mixture of branched-chain fatty acid methyl esters (iii) and QUAL MIX BR4 standard mixture of branched-chain fatty acid methyl esters (iv) 

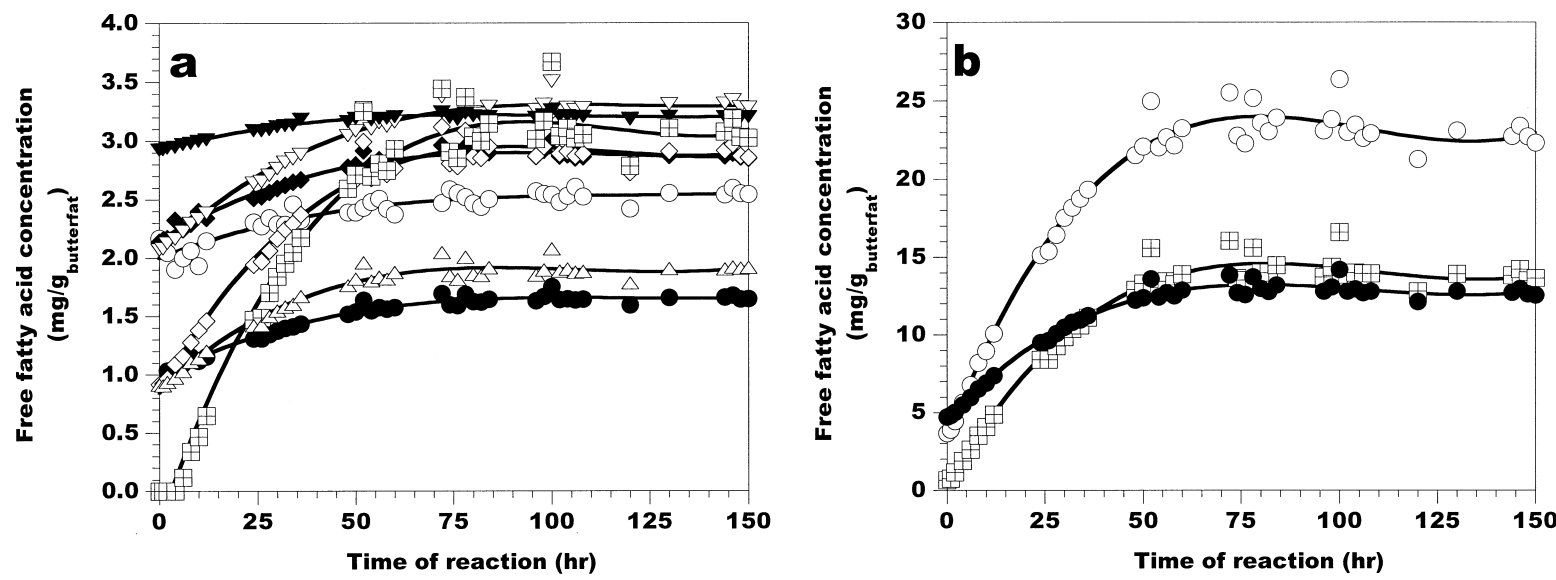

Figure 4 Evolution of the concentrations of free $(\mathbf{a})$ butyric $(\bigcirc)$, caproic $(\bullet)$, caprylic $(\diamond)$, capric $(\nabla)$, lauric $(\diamond)$, linolenic $(\nabla)$, myristic $(\boxplus)$ and linoleic $(\triangle)$ acids, and free (b) palmitic $(\bigcirc)$, oleic $(\boxplus)$ and stearic $(\bullet)$ acids in plain butterfat undergoing lipase-catalyzed interesterification

overall composition of plain butterfat as depicted in these Figures, the average molecular weight of fatty acids esterified in butterfat is estimated as $212.5 \mathrm{~g} \mathrm{~mol}^{-1}$. Furthermore, assuming that the glyceride pool of butterfat is composed solely of triacylglycerol molecules and taking the density of butterfat at $40^{\circ} \mathrm{C}$ to be $0.905 \mathrm{~g} \mathrm{ml}^{-1},{ }^{17}$ then the theoretical amount of fatty acids that could ever be released from butterfat by hydrolysis would be approximately 918.9 g FA kg ${ }^{-1}$ butterfat. Combining this value with Figures 4 and 5, one finally concludes that net overall hydrolysis of butterfat after startup ocurred to an extent of approximately $5.3 \%$ and $2.3 \%$ in the interesterification of plain butterfat and in the acidolysis of butterfat with oleic acid, respectively.

The triacylglycerols of plain butterfat displayed after $150 \mathrm{~h}$ a net reduction of esterified fatty acids. Although sequential net hydrolysis and net ester synthesis were found to take place in the triacylglycerols of plain butterfat (Figure 6), the former prevailed by the end of the experimental reaction period. The triacylglycerols of butterfat interesterified with oleic acid had significantly more $(29.4 \%)$ oleic acid residues and significantly less (in average $7.5 \%$ ) saturated fatty acid residues by the end of the reaction time frame when compared with startup conditions. In particular, they had $7.8 \%$ less lauric and $2.1 \%$ less myristic acid residues than those of the original butterfat as depicted in Figure 7. As can also be observed in Figure 7, fatty acid residues with fewer than 12 carbon atoms remained at a virtually constant concentration throughout the $150 \mathrm{~h}$ of reaction. These findings confirmed that the proposed goal of having oleic acid incorporated without effecting major changes in the inventory of small-chain fatty acid residues was achieved.

The total composition of fatty acid residues throughout reaction time is depicted in Figure 8 for the triacylglycerols of plain butterfat that underwent interesterification and for butterfat that underwent acidolysis with oleic acid. As apparent in Figure 8, net hydrolysis took place in the case of interesterification of plain butterfat whereas net ester
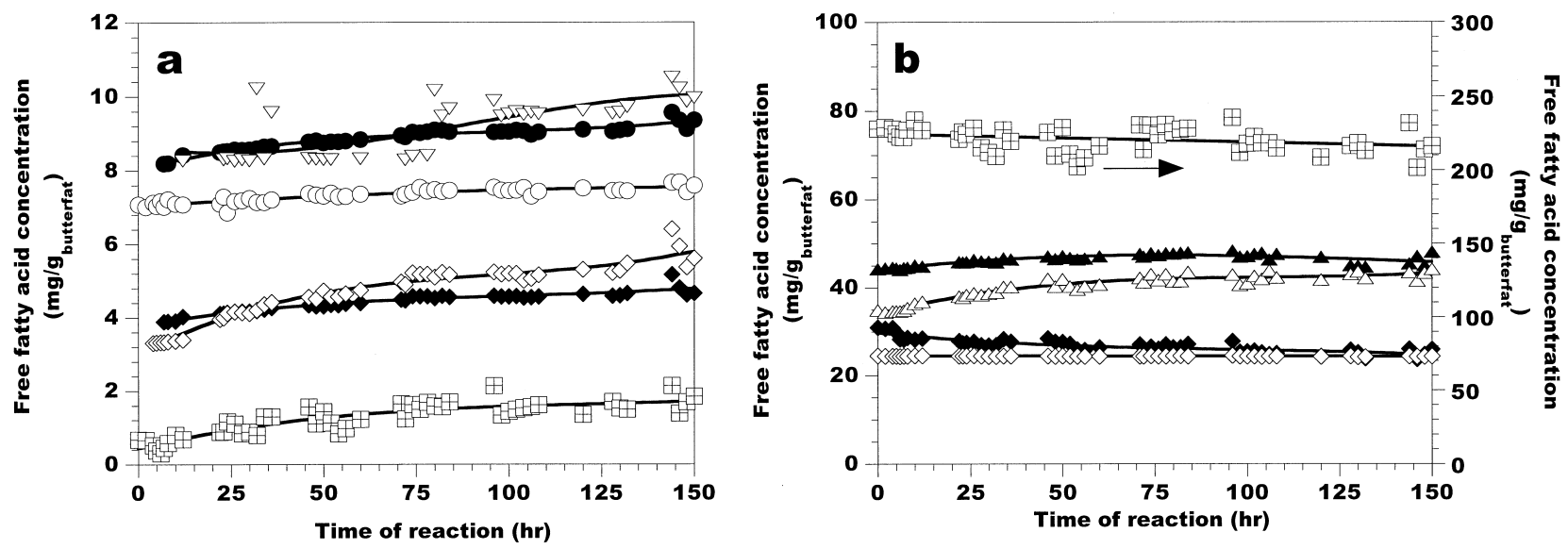

Figure 5 Evolution of the concentrations of free $(\mathbf{a})$ butyric $(\bigcirc)$, caproic $(\diamond)$, caprylic $(\bullet)$, capric $(\nabla)$, lauric $(\diamond)$ and myristic $(\boxplus)$ acids, and free $(\mathbf{b})$ palmitic $(\triangle)$, stearic $(\mathbf{\Delta})$, oleic $(\boxplus)$, linoleic $(\diamond)$ and linolenic $(\diamond)$ acids in butterfat undergoing lipase-catalyzed acidolysis reaction 


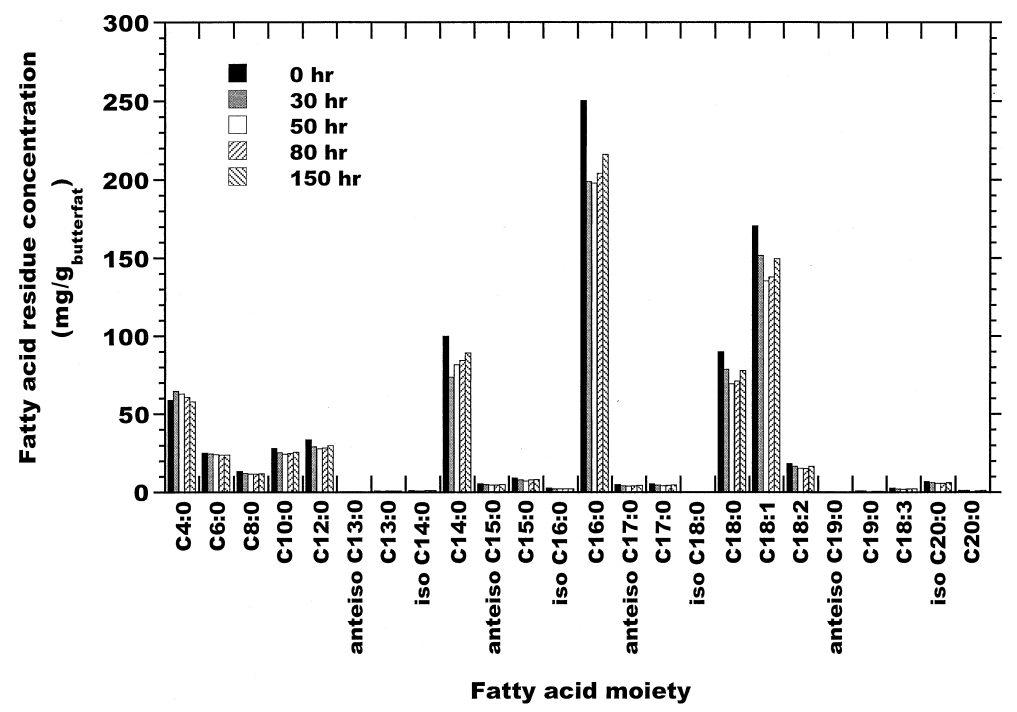

Figure 6 Composition of fatty acid residues as a function of reaction time in plain butterfat after lipase-catalyzed interesterification

synthesis occurred when free oleic acid was added to the reaction medium.

\section{Discussion}

Performance of the lipase-catalyzed reaction using the hollow-fiber setup described above led to a preferential net release of fatty acid residues of medium-chain length, in particular, lauric acid (3.1- and 1.7-fold increases in fatty acid in free form for interesterification of plain butterfat and acidolysis of butterfat with oleic acid, respectively) and myristic acid (25.1- and 2.7-fold increases in fatty acid in free form for interesterification of plain butterfat and acidolysis of butterfat with oleic acid, respectively), and of long-chain length, in particular palmitic acid (6.1- and 1.3 -fold increases in fatty acid in free form for interesteri- fication of plain butterfat and acidolysis of butterfat with oleic acid, respectively). These findings are consistent with the reported substrate specificity of $M$. javanicus lipase. ${ }^{18}$ As can also be concluded from inspection of Figures $4 a$ and $5 a$, short-chain fatty acid moieties remained virtually unaffected in both cases, thus confirming the limited specificity of the aforementioned fungal lipase toward short-chain fatty acids. Branched-chain fatty acids (mainly accounted for by iso-C14:0, iso-C16:0, iso-C20:0, anteiso- $\mathrm{C} 15: 0$ and anteiso-C17:0) were found to exist in little amounts in the triacylglycerols of both native butterfat and lipase-modified butterfat; total iso-fatty acid residues were determined as approximately $1.0 \%$ and $0.9 \%(\mathrm{w} / \mathrm{w})$ of total mass of original butterfat used both in interesterification and acidolysis reactions, and similar percentages were found for total anteiso-fatty acid residues. The levels of both iso- and

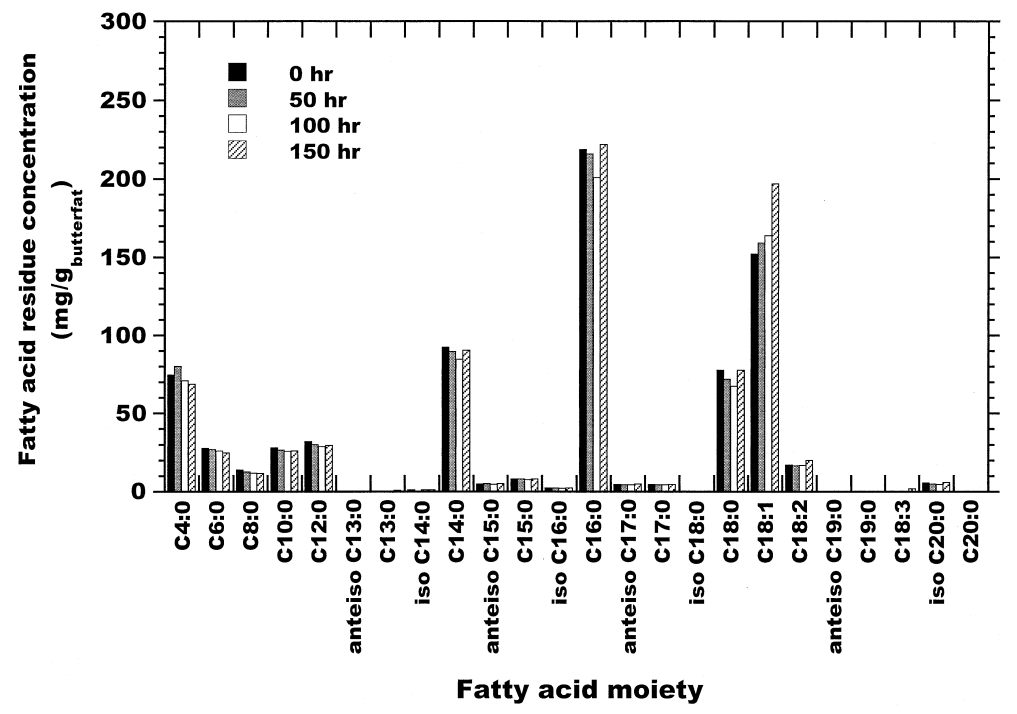

Figure 7 Composition of fatty acid residues as a function of reaction time in butterfat with oleic acid after lipase-catalyzed acidolysis 


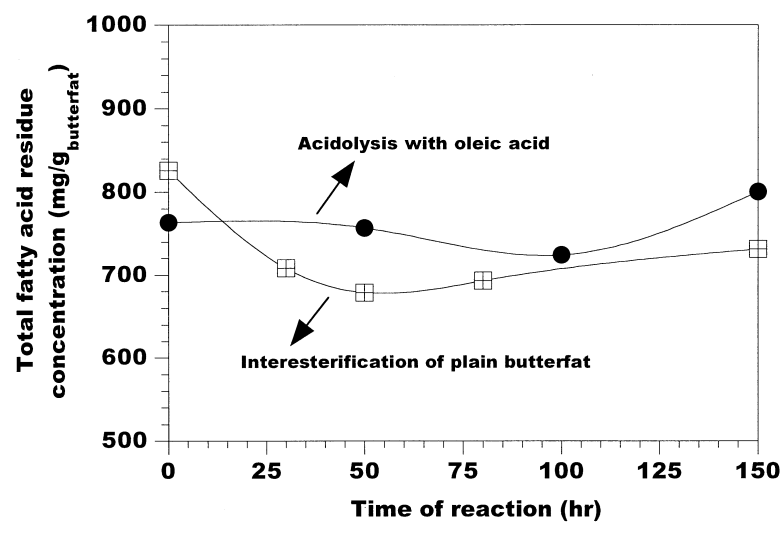

Figure 8 Evolution with time of the total composition in fatty acid residues of plain butterfat undergoing lipase-catalyzed interesterification $(\boxplus)$ and of butterfat with oleic acid undergoing lipase-catalyzed acidolysis (

anteiso-fatty acid residues remained virtually constant throughout reaction time, thus suggesting a virtually nonexisting specificity of the microbial lipase used toward such branched fatty acids.

Interesterification of plain butterfat led to a preferential net release of medium-chain saturated fatty acids (especially myristic acid), but this release was somewhat hindered when oleic acid was deliberately added to the reaction medium (Figure 5a). Furthermore, while in interesterification of plain butterfat, oleic acid was liberated to a considerable extent (20.4-fold increase of this fatty acid in free form) when free oleic acid was added to the medium lipase-mediated incorporation into the triacylglycerols of butterfat was triggered. The concentration of free oleic acid in the reaction medium was reduced up to approximately $5.1 \%$ when acidolysis of butterfat was considered which corresponds to a rate of incorporation of approximately 77 $\mu \mathrm{g} \mathrm{h}^{-1} \mathrm{~g}^{-1}$ butterfat, thus indicating a reasonably high degree of incorporation in engineered butterfat (Figure 7). These results do somewhat conflict with a previous report by Dewettinck et al. ${ }^{19}$ who claimed that the pool of free fatty acids remains virtually unaffected during interesterification of plain milkfat. The results obtained in our research effort show an initial increase in the concentration of free fatty acids (due to net hydrolysis which can probably be accounted for by traces of aqueous buffer trapped inside the hollow fibers) followed by a decrease as time elapses (due to ester synthesis) which is in agreement with Goderis et $a l .{ }^{20}$ who reported that during the initial stages of interesterification, a portion of the triacylglycerols is hydrolyzed, thus consuming water and releasing free fatty acids, but that after this transient step has elapsed, interesterification proceeds smoothly because the pool of water molecules available has been lowered and tends to stay at that level in a balanced fashion.

The results obtained in this work indicate that desired alterations in the glyceride composition of butterfat can be induced by use of a specific lipase, and so lipase-catalyzed interesterification of butterfat appears to be a technically feasible alternative to physical blending of fats or sodium methoxide-catalyzed interesterification of butterfat when a smaller content of myristic acid residues, and concomitantly higher content of oleic acid residues, are sought. Once in free form, the former (undesirable) fatty acid could then be removed by extraction, such as using 1,2-butanediol/water $(20: 1 \mathrm{v} / \mathrm{v})$ as solvent. ${ }^{21}$ Alternatively, a nutraceutical butter (or butter substitute) possessing a higher degree of (mono)unsaturation and good physicochemical stability can be obtained when plain butterfat is mixed with free oleic acid and then subject to acidolysis catalyzed by this microbial lipase.

\section{Conclusions}

A lipase from $M$. javanicus, immobilized by adsorption onto polypropylene hollow fibers, displayed a reduced specificity toward short-chain and a high specificity toward medium- and long-chain fatty acids from butterfat triacylglycerols, and so was a suitable biocatalyst for the controlled modification of butterfat. The interesterification of butterfat with oleic acid catalyzed by this lipase resulted in the exchange of myristic, palmitic and stearic acids in the triacylglycerols of butterfat with free oleic acid added to the medium; therefore, use of this lipase will likely lead to maintenance of the basic aroma profile of butterfat (which is associated mainly with short-chain fatty acids) and improvement of the nutraceutical value via exchange of (hypercholesterolemic) saturated medium-chain fatty acid residues with (hypocholesterolemic) unsaturated oleic acid residues.

\section{Acknowledgments}

Partial funding for this research effort was provided through grants by FLAD (Portugal; Project Lipase-catalysed interesterification of butterfat with olive oil) and by Institut CANDIA (France; Project Modification de la matière grasse par des lipases immobilisées sur un réacteur à membrane). Funding for author V. M. Balcão was provided through a Ph.D. fellowship by JNICT (Portugal; CIENCIA BD/2091/92-IF and PRAXIS XXI BD/5317/95).

\section{References}

1. Davide, C. L. New directions in low-fat dairy products processing towards better health. Philippine Agri. 1994, 77, 1-16

2. Ney, D. M. Potential for enhancing the nutritional properties of milkfat. J. Dairy Sci. 1991, 74, 4002-4012

3. Oba, T. and Witholt, B. Interesterification of milkfat with oleic acid catalyzed by immobilized Rhizopus oryzae lipase. J. Dairy Sci. 1994, 77, 1790-1797

4. Renner, E. and Gurr, M. Do we need cholesterol reduced dairy products? Dairy Ind. Int. 1991, 56, 34-35

5. O'Donnell, J. A. Future of milkfat modification by production or processing: Integration of nutrition, food science, and animal science. J. Dairy Sci. 1993, 76, 1797-1801

6. Glaeser, H. and Keane, M. Cholesterol-reduced dairy productshealthy or harmful? Dairy Ind. Int. 1992, 57, 39

7. Kimoto, H., Endo, Y., and Fujimoto, K. Influence of interesterification on the oxidative stability of marine oil triacylglycerols. J. Am. Oil Chem. Soc. 1994, 71, 469-473

8. Marangoni, A. G. and Rousseau, D. Engineering triacylglycerols: The role of interesterification. Trends Food Sci. Technol. 1995, 6, $329-335$ 
9. Vulfson, E. N. Enzymatic synthesis of food ingredients in low-water media. Trends Food Sci. Technol. 1993, 4, 209-215

10. Thomas, K. C., Magnuson, B., McCurdy, A. R., and GrootWassink, J. W. D. Enzymatic interesterification of canola oil. Can. Inst. Food Sci. Technol. J. 1988, 21, 167-173

11. Yamane, T., Suzuki, T., and Hoshino, T. Increasing $\omega-3$ polyunsaturated fatty acid content of fish oil by temperature control of lipase catalysed acidolysis. J. Am. Oil Chem. Soc. 1993, 70, 1285-1287

12. Kalo, P., Huotari, H., and Antila, M. Pseudomonas fluorescens lipase-catalysed interesterification of butterfat in the absence of a solvent. Milchwiss. 1990, 45, 281-285

13. Balcão, V. M. and Malcata, F. X. Lipase-catalyzed modification of butterfat via acidolysis with oleic acid. J. Mol. Catal. B: Enzymatic 1997, 3, 161-169

14. Balcão, V. M., Vieira, M. C., and Malcata, F. X. Adsorption of protein from several commercial lipase preparations onto a hollowfiber membrane module. Biotechnol. Prog. 1996, 12, 164-172

15. Garcia, H. S., Reyes, H. R., Malcata, F. X., Hill, C. G., and Amundson, C. H. Determination of the major free fatty acids in milkfat using a three-component mobile phase for HPLC analysis. Milchwiss. 1990, 45, 757-759
16. Badings, H. T. and De Jong, C. Glass capillary gas chromatography of fatty acid methyl esters. A study of conditions for the quantitative analysis of short- and long-chain fatty acids in lipids. J. Chromat. 1983, 279, 493-506

17. Kurtz, F. E. The lipids of milk: Composition and properties. In: Fundamentals of Dairy Chemistry (Webb, B. H. and Johnson A. H., Eds.). AVI Publishing Company, Westport, CT, 1965, 161

18. De Greyt, W. and Huyghebaert, A. Lipase-catalyzed modification of milkfat. Lipid Technol. 1995, 7, 10-12

19. Dewettinck, K., De Greyt, W., and Huyghebaert, A. Lipasecatalysed interesterification of milkfat: Influence on the free fatty acid profile. Med. Fac. Landbouw. Univ. Gent. 1992, 57 (4b), 1905-1907

20. Goderis, H. L., Ampe, G., Feyten, M. P., Fouwé, B. L., Guffens, W. M., Van Cauwenbergh, S. M., and Tobback, P. P. Lipasecatalyzed ester exchange reactions in organic media with controlled humidity. Biotechnol. Bioeng. 1987, 30, 258-266

21. Keurentjes, J. Physical chemistry and engineering of membranes for fat/fatty acid separations. Ph.D thesis, University of Wageningen, Holland, 1991, 7 